\title{
Architectural Education Adapting to Climate Challenges in Light of Feng-Shui
}

\author{
Ping Xu \\ Program in Environmental Design, University of Colorado Boulder, United States
}

Copyright $(2016$ by authors, all rights reserved. Authors agree that this article remains permanently open access under the terms of the Creative Commons Attribution License 4.0 International License

\begin{abstract}
Weather challenges have become a significant issue for our society in recent years. Thousands of people have lost their homes and lives. Buildings designed without taking into account wind and water factors have repeatedly been destroyed during natural disasters. These problems in practice reflect the weak points in education. Our ancestors adapted to the climate and built their architecture to respond to nature for survival. Feng-shui, a Chinese practice, is used to harmonize people with their environment and to advise people to avoid natural disasters. Vernacular houses in many cultures are the precedents of sustainable design. The author has integrated her research into teaching including a lecture course and a senior undergraduate architectural design studio with the theme of adapting to climate challenges. Using feng-shui as a clue, these courses introduce scientific concepts that emphasize Rocky Mountain geographic conditions and identification of landform patterns in the high impact zones of natural hazards. Discussions on adapting to climate challenges encompass a wide range, from large scale to small scale; from landscape analysis to architectural design; and from natural disasters to human attitude. With an integrated knowledge base and an emphasis on spatial design, architectural education could contribute to adapting to climate challenges. Applying a synthesis approach will be the direction of the future of education and practice.
\end{abstract}

Keywords Architectural Education, Climate, Adaptation, Vernacular, Feng-shui, Synthesis Approach

\section{Introduction}

Current extreme weather patterns and natural disasters have led to the loss of thousands of homes and lives. In 2012, Hurricane Sandy in the United States killed 159 people and caused $\$ 75$ billion in damages [6]; and in 2005 Hurricane Katrina killed 1,836 people and caused $\$ 108$ billion in damages [9]. The historic 2013 Colorado floods killed 10 people and caused \$4 billion in damages [1].

Even though natural hazards are beyond human control, rapid development throughout the world has altered the ecological balance and led to "nature's revenge." To build a home on the beach, a cultural luxury, not only jeopardizes the fragile coastal eco-system [13] but also places humans in danger during storms. In the U.S., houses in coastal areas are built identically to inland homes, and houses in high-risk regions for tornadoes are constructed similarly to those in low-risk cities. Buildings designed with disregard for wind patterns have repeatedly been destroyed during windstorms. Fisher [7] stated "we designed our way into these disasters, and we can design our way out of them by understanding the nature of our errors. We should not simply repeat them, as we have been doing over and over in recent decades". These problems in practice reflect the weak points in education. As the products of architects, buildings are responsible for over $40 \%$ of pollutant emissions and energy consumption in the world [22], but this fact has escaped the attention of architectural education until the recent decade. Conventional architectural education emphasizes artistic creativity and ignores design constraints and environmental issues. This paper explores a synthesis approach to architectural education in adapting to climate challenges, and emphasizes learning from Chinese vernacular wisdom, precedents, and particularly feng-shui, the traditional Chinese practice used to harmonize people with their environment, which literally translates to "Wind" and "Water."

\section{Attitudes toward Adapting to Climate Challenges}

\subsection{Attitudes and Action}

Faced with natural disasters, humans respond with three main attitudes. The first attitude is over-optimistic; the belief that humans can have power over nature. When nature causes trouble, these people want to "beat nature back." However, with increasingly frequent natural disasters around 
the world, fewer and fewer people have this mentality. The second attitude is over-pessimistic; the feeling that natural disasters are out of people's control, creating a resistance to acknowledging the issue. The people with this mentality wish that every natural disaster would not repeat during their lifetime. The third attitude is that we must adapt to climate challenges to sustain our society. As Darwin [5] posited, "It is not the strongest of the species that survives, nor the most intelligent, but rather the one most adaptable to change". Natural systems move in periodic cycles, with good years and bad years. In this cycle, Mother Nature takes on two faces: a nice face and a dangerous face. Throughout history, architecture has been impacted by forces of climatic disasters [16], including fire, hurricanes, tornadoes, drought, flooding, debris/mudflows, snowstorms, and hail.

People all over the world have sustained themselves for thousands of years by adapting to climate challenges. Western architecture, particularly fortresses along coasts, provides an excellent example of architecture constructed for defense purposes, as well as protection from hurricanes and windstorms. Most fortresses are built on carefully selected sites, primarily chosen for their strategic defensive abilities, and for rocky terrain that doesn't wash away easily like a sand beach. Fortresses were often designed with sunken courtyards, allowing the military to lead a relatively routine life. The existing fortresses in Europe and the U.S. have retained their shape for hundreds of years, a testimony to their strength after many hurricanes and windstorms. Being set back from the coastline is also important, as illustrated in the 1620 settlement of Plymouth, Massachusetts. When the pioneers from Britain landed on the coast, they built their residences and graves up on the hills, never directly along the attractive beach. They considered survival as their priority, a much wiser mentality than some contemporary viewpoints. In the East, folk practices and belief systems service to sustain their environment.

\subsection{Worship Sustains the Natural Environment}

Our ancestors have experienced similar forces presented by climate challenges. According to Chinese historical records of “后汉书,” in April of 119 AD, along the coast of the Bohai Sea near Beijing, windstorms dug more than 30,000 trees from the ground [11]. Ancient Chinese people believed that such hazards occurred due to human misconduct, making Mother Nature angry. Honoring nature with care and respect, the ancient people adapted to climate challenges and built their architecture in response to nature in order to survive.

The ecosystem in the high plateau of Tibet is very vulnerable. At such high elevations, vegetation hardly grows, and if destroyed will result in erosion and debris/mudflows. Tibetans have experienced this power of nature and realize that it is beyond human control. They imagine these forces as "demons" and "gods." Tibetans believe that anytime a mountain, the earth, or a river is disturbed, the "demons" will be upset, and will take revenge
[15]. Tibetans must pray to show respect, stop disasters, and aid their survival, which furthers their attempts not to destroy, or even change the natural environment. Every time a new road is built, prayer flags are hung. These colorful flags are often placed on the hillside and inscribed with Buddhist sutras, which "chant with the winds" and prevent "demons" from making trouble (Figure 1). Worship of nature serves as the means to control human's demands on nature. As a result, the vulnerable ecosystem is sustained, which allows humans to survive.

Similar to Tibetans, the traditional Chinese often hire a feng-shui practitioner to analyze the conditions of a building site. Before people dig the dirt, the feng-shui master must examine the position and conditions of the site and make sure nothing will offend the "super god", 太岁, otherwise a catastrophe will befall their family. Corresponding to this traditional attitude, article 4-806 of the Boulder County Land Use Code (Code 4, 6, 11 and 12) requires that people not alter existing drainage systems. Excessive site disturbance can cause problems with runoff and erosion, and can trigger potential natural hazards [2]. The care for the land and worship of the earth seen today is an ecological conscience and an environmental ethic, the essential aspects of architectural education for creating a sustainable environment.

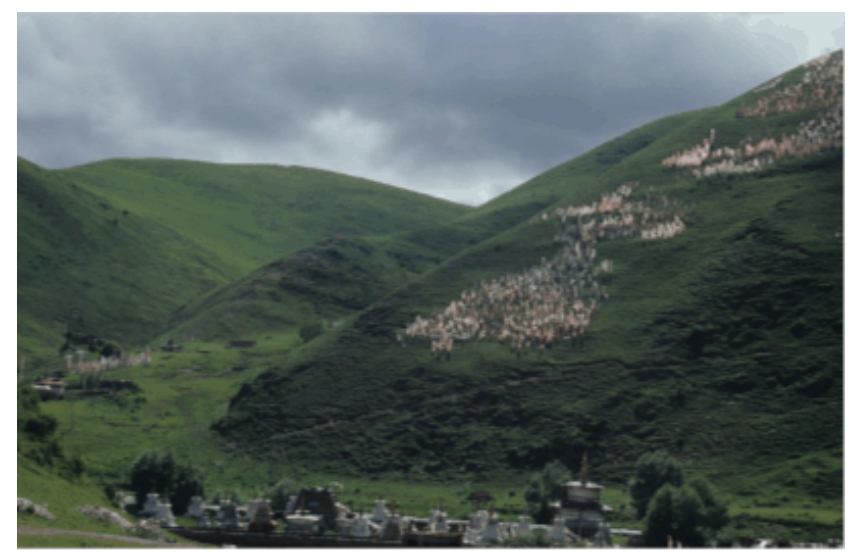

Figure 1. Prayer flags on the hill nearby the Tagong temple in Sichuan Province which "chant with the winds" to protect the temple and drive evils away. (Photo by Ping Xu)

\section{Architectural Education in Light of Feng-shui}

The author has integrated her research into teaching including a lecture course and a senior undergraduate architectural design studio with the theme of adapting to climate challenges. These courses introduce scientific concepts with an emphasis on Rocky Mountain geographic conditions and identifying the landform patterns in the high impact zones of natural hazards, using feng-shui as a clue. Discussions on adapting to climate challenges encompass a wide range, from large scale to small scale; from landscape analysis to architectural design; and from natural disasters to human attitude. 


\subsection{Landscape Analysis: Identifying Landform Patterns of Debris/Mudflow Zones}

Boulder, Colorado is one of the most desirable towns to live in due to its beautiful surrounding landscape, healthy living conditions, and 300 days of sun per year. However, its high elevations and mountain geographic conditions contribute to the occurrence of natural disasters. Many characteristics of the Rocky Mountain region, including steep slopes, exposed bedrock, thin soil, and shallow tree roots, provide an abundant debris source. Intense thunderstorms with lightning can spark forest fires. The Chinook winds and the highest peak gusts in the nation can damage properties and spread fire rapidly over thousands of acres. The increasing residential population, dense development, and frequency of fires in the mountains is changing the vulnerable systems on the steep hillsides, generating debris and accelerating erosion.

The high impact zones of the historic 2013 Colorado floods provide a living textbook for learning about natural hazards, particularly those impact zones that experienced a fire prior to the flooding. Using feng-shui as a clue, students learn and identify the landscape patterns of debris/mudflow zones affected by the postfire sequence in Colorado Front Range canyons. A debris/mudflow is one of the most dangerous natural hazards [3]. It is different from a "spring runoff" flood, which usually involves water rising from spring snowmelt that runs over the bank and floods the land. A debris flow comes from a higher elevation with great force. It can climb several feet high and knock over houses.

Students learn the significant agreement between feng-shui principles and geomorphic concepts in identifying landform patterns of debris/mudflow zones. According to geomorphic research, there are three main debris/mudflow zones. The first zone is the debris catchment area, which provides an abundant debris source. The second is the debris flow track; these are the landforms that generate the speed and power of the debris flow as it proceeds downstream. The third zone is the debris flow fan, which is the receiving area of the debris flow [17, 18]. These geomorphic concepts correspond with feng-shui classifications, which combined form a group of criteria for the author's field investigations that were introduced in her class. The corresponding categories are as follows; the debris catchment zone corresponds to feng-shui's "Mountain and Canyon" and "Hill"; the debris flow track corresponds to feng-shui's "Water"; and the debris flow fan corresponds to feng-shui's "Site."

Feng-shui practice first looks at the larger scale, the mountains and canyons (Figure 2). The "dead dragon" and the "sick dragon" often create the landform of a vast basin in the upper portion of the canyon [25]. A dry wash or small creek originates from this high basin, rich in debris. The hillside where the dry wash passes through has a constant slope of $35 \%-45 \%$. During torrential rains, the runoff with debris is washed into the narrow flow track, and generates violent power as it proceeds downstream. Geomorphic research by Reneau and Dietrich [18] demonstrates that two-thirds of failures initiate within the basin. Therefore an emphasis on both the basin and the flow tracks from upslope is significant in identifying the hazard. Hills adjacent to the site are also included in this category. Feng-shui states that even gradients on a hillside can cause floods [12] as a smooth slope readily forms straight gullies. The "fire hill," which rises to a straight sharp point, should also be avoided as it can cause fire [25].

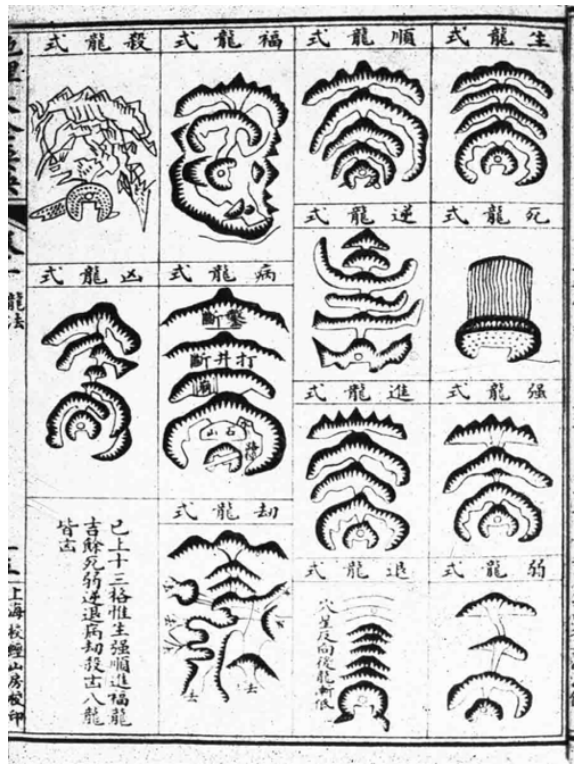

Figure 2. The feng-shui diagram presents the unfavorable mountains (Source: Shike Xu [25], Di Li Tian Ji Hui Yuan, 1580)

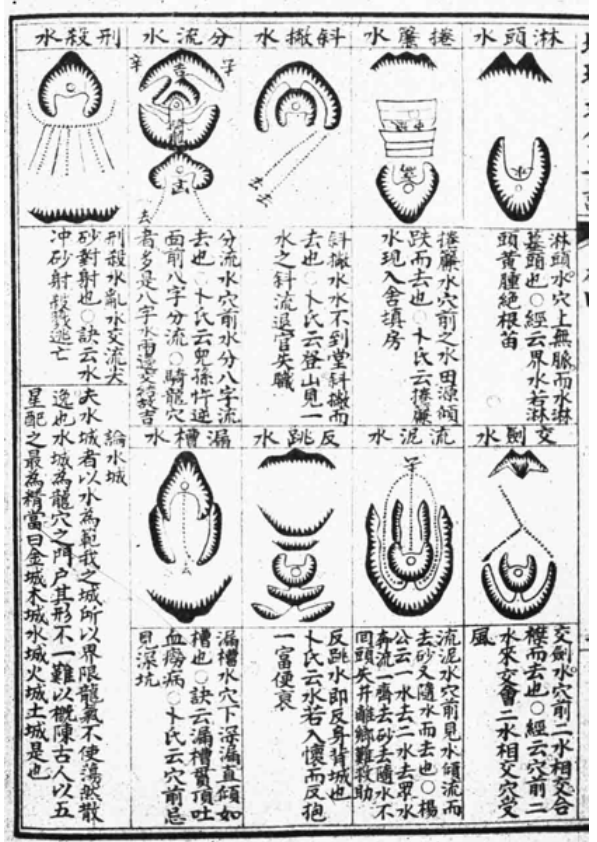

Figure 3. The feng-shui diagram demonstrates the unfavorable types of water (Source: Jiusheng Ye [26], Di Li Da Cheng, 1688) 
In feng-shui, the straight channels of rivers, creeks, and dry washes, the debris flow tracks, also pose debris/mudflow issues (Figure 3). When the flow track changes direction quickly, there is potential for disaster. If the site is on the outside of the curve of a river, it is known in feng-shui as a "water shooting heart." A straight dry wash is the most dangerous water channel if it is on a hill behind the site. The dry wash triggers a debris/mudflow, known as the "water showering head" [26].

When a debris/mudflow meets the debris flow fan or site where the slope suddenly drops more than $20 \%$, the debris/mudflow releases the debris onto the impact area, which has a gentle $10-15 \%$ slope. During debris flow events the confluence of two flow tracks can receive twice the damage, from both a "water showering head" and a "water shooting heart." The highest impact areas in the Colorado Front Range Canyons also often have local hills with steep slopes, which have seen fire recently. When the debris flows from these hills dam the rivers, it causes even more flooding.

The debris/mudflows following mountain fires, called the postfire-debris flow sequence, are common. Fire changes the structure of soil and creates erosion [21]. Dry debris, which flows into channels immediately after a fire, can create a dam in dry washes, worsening future debris flows [4]. These postfire erosions can accelerate and intensify a debris/mudflow disaster [21]. After a fire, it is crucial to anticipate and prepare for powerful debris/mudflows.

Figure 4 shows student field investigations at the high impact area of the 2013 debris/mudflows in Chapel on the Rock, Allenspark, Colorado. This site, which has about a 7\% slope, received a heavy debris/mudflow on September 12th, 2013. The area also experienced a fire in 2011. The debris/mudflow buried roads near the Chapel in a layer of mud and tree chips over 100 feet wide and 6 feet high. This debris flow came from five miles away, at Mt. Meeker. The flow was so violent that huge trees in its path were pulverized to woodchips by the time they reached the receiving area. The mountain's peak, high above the tree line, has a large basin area covered with broken rocks and sand, and a constant $38 \%$ slope. In feng-shui practice, it fits the definition of a "sick dragon," and a "dead dragon." The small creek originates from a high elevation, and passes through a straight channel with steep slopes, generating a debris/mudflow with heavy rain. Students learn that natural disasters often result from a large-scale landscape. The contributing zones can be far outside the boundary of a master plan. Landscape analysis and site selection with larger scale considerations will be crucial to avoid future failures.

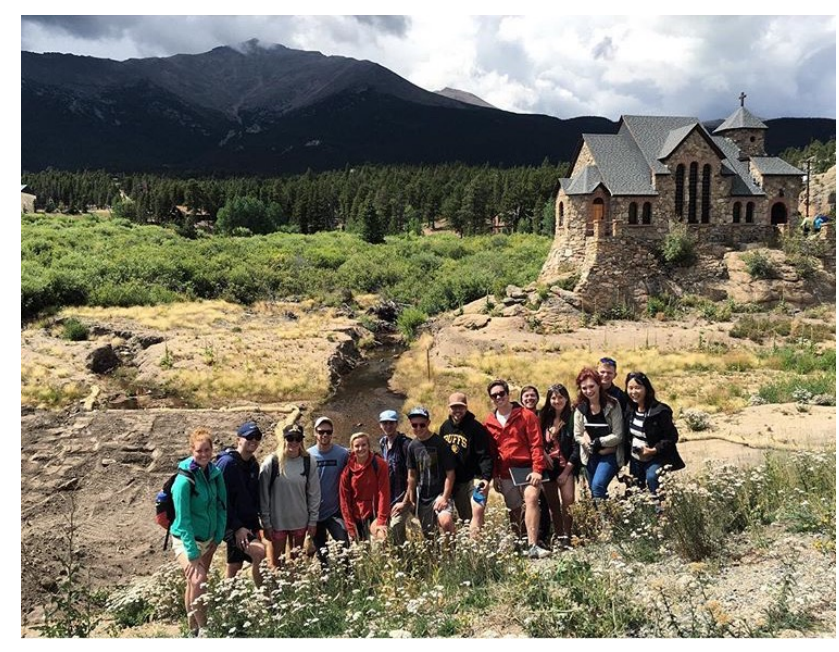

Figure 4. Student field investigations at the 2013 Colorado flood high impact zone, Chapel on the Rock, Allenspark, Colorado (Photo by Natalie Jorge)

\subsection{Architectural Design: Avoid Cold Winds}

According to feng-shui, people should avoid cold winds like they avoid a thief. In northern China, a favorable feng-shui site is in a contained mountainous area, enfolded by hills and protected from prevailing cold winds. The site is open to the south, has a view of mountain peaks in the south, and has a meandering river passing through (Figure 5) [27]. Following this ideal feng-shui model, the traditional Beijing courtyard houses were designed to protect residents from windstorms and to accumulate $q i$, the vital energy. Windows face the interior courtyard, while the exterior of the home has no windows at all. The gate of the courtyard is set in the southeast corner to receive the living qi from this direction [23].

Cave dwellings in China have thousands of years of history; in 1980, about 100 million Chinese still lived in cave dwellings [8]. The sunken courtyards of the cave dwellings in the Loess Plateau of northern China provide storm protection (Figure 6). The layer of loess soil can reach 300 meters in thickness, offering a great opportunity for local people to dig out a courtyard with surrounding rooms. This is also an economical solution to building a home. This kind of dwelling meets requirements for an ordinary quality of life. The sunken courtyards provide air and sunshine and collect water that is then stored within the dwellings. They even provide space to feed animals and grow plants and fruit trees. The homes are accessible by road systems built to reach below ground level. This allows for transportation in and out of the village as well as provides access to the roofs of each home, which are yards for peasants to grind grains and winnow. These cave dwellings serve as an example of integrating functional spatial design with local techniques in adapting to climate challenges. 


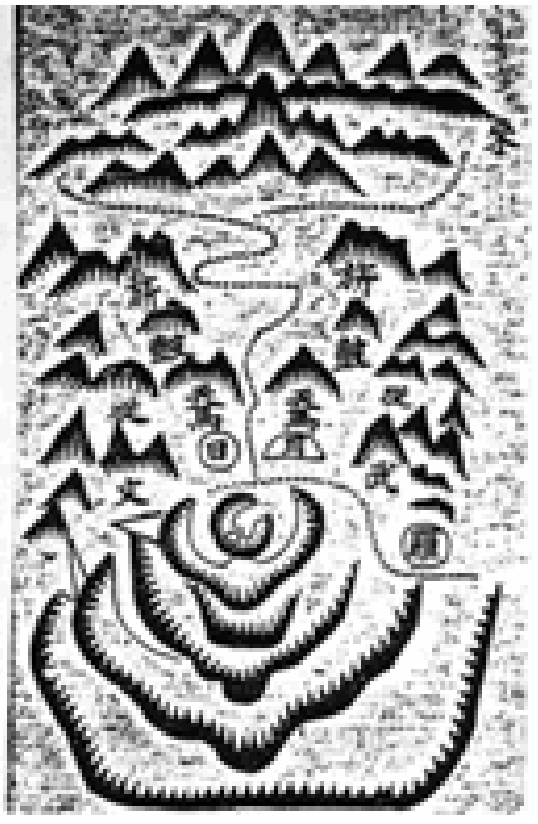

Figure 5. This ancient Chinese map shows an ideal feng-shui model for a house site. (Source: Tingyou Zou [27]. Di Li Da Quan, 1676.)

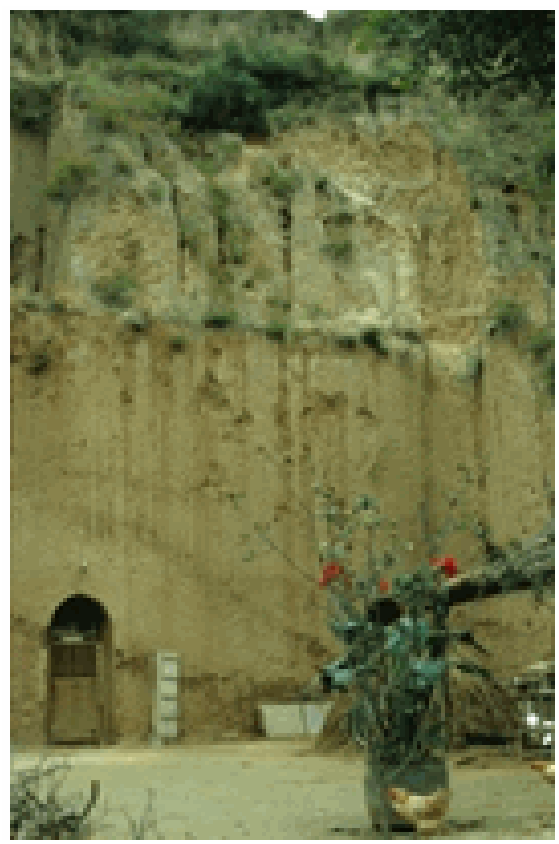

Figure 6. Cave dwellings in Henan Province, China (Photo by Ping Xu)

Tibetan houses and villages are located 3,000 meters above sea level [24]. The air is thin, and the weather is unpredictable with frequent snowstorms. In Tibetan buildings, the trapezoidal shape is an important, repeated element. The outside walls are thick and tapered up, giving the building a form that is more stable during snowstorms. Windows are often designed with small openings that are angled down through the walls. To keep warm in winter and avoid harmful radiation from the sun, the small, trapezoidal windows create a very dark interior. These openings allow light to enter the space while maintaining interior warmth. Due to the dry weather and minimal rain runoff, the roofs of Tibetan houses are flat. To suppress evil factors, branches decorated with prayer flags are placed at the corners of the roof. Tibetans believe the color white can drive evil away. White also reflects heat and strong radiation from the sun, while maintaining structural stability. These characteristics of vernacular houses are the result of adapting to the harsh climate and serve to sustain Tibetan architecture in the Qingzang Plateau.

\section{Practice in Design Studio Education}

Learning from vernacular wisdom and precedents, the undergraduate senior architecture studio taught by the author explored the topic of design with adaptation to climate challenges. By integrating the geographic information of local climate and hazards into the site analysis and architectural design, this studio explored solutions for new types of architecture. Design projects, including a community cultural center and a hostel, focused on the issues of windstorms and debris/mudflows in Boulder, which has some of the highest peak winds of any city in the United States [20] and experienced high impacts during the historic 2013 floods. This studio introduces the author's integrative design process model. In every section there is a single focus on architectural and landscape design as well as for the design process. Students, using a step-by-step process, created their work more independently and fruitfully (Figure $7)$.

\subsection{Suitability Analysis}

A landscape suitability analysis was an emphasized component of this architecture studio. After an investigation of the Mesa Trail, Boulder, students collaborated in teams to produce a suitability analysis map using ArcGIS (Geographic Information Systems). This study attempted to minimize the ecological impacts on water quality, wetlands, wildlife habitats, erosion, debris/mudflow zones, and vegetation while avoiding areas of high wind risk such as northwest-facing slopes, the crest of hills, wind tunnels, and dry washes. The study also sought to maximize the well being of site users by selecting south-facing slopes for solar exposure that also protect the site from cold winds in winter and provide breezes in summer. The process of suitability analysis combined insights from both modern methods and the ancient principles of feng-shui. Existing geographic information data provided by Boulder County and national sources was also utilized. A GIS map presented the studio's final site selection, which avoided constrained areas, including the ecologically vulnerable and natural hazard areas, and provided more benefits, such as south-facing gentle slopes and good views. 


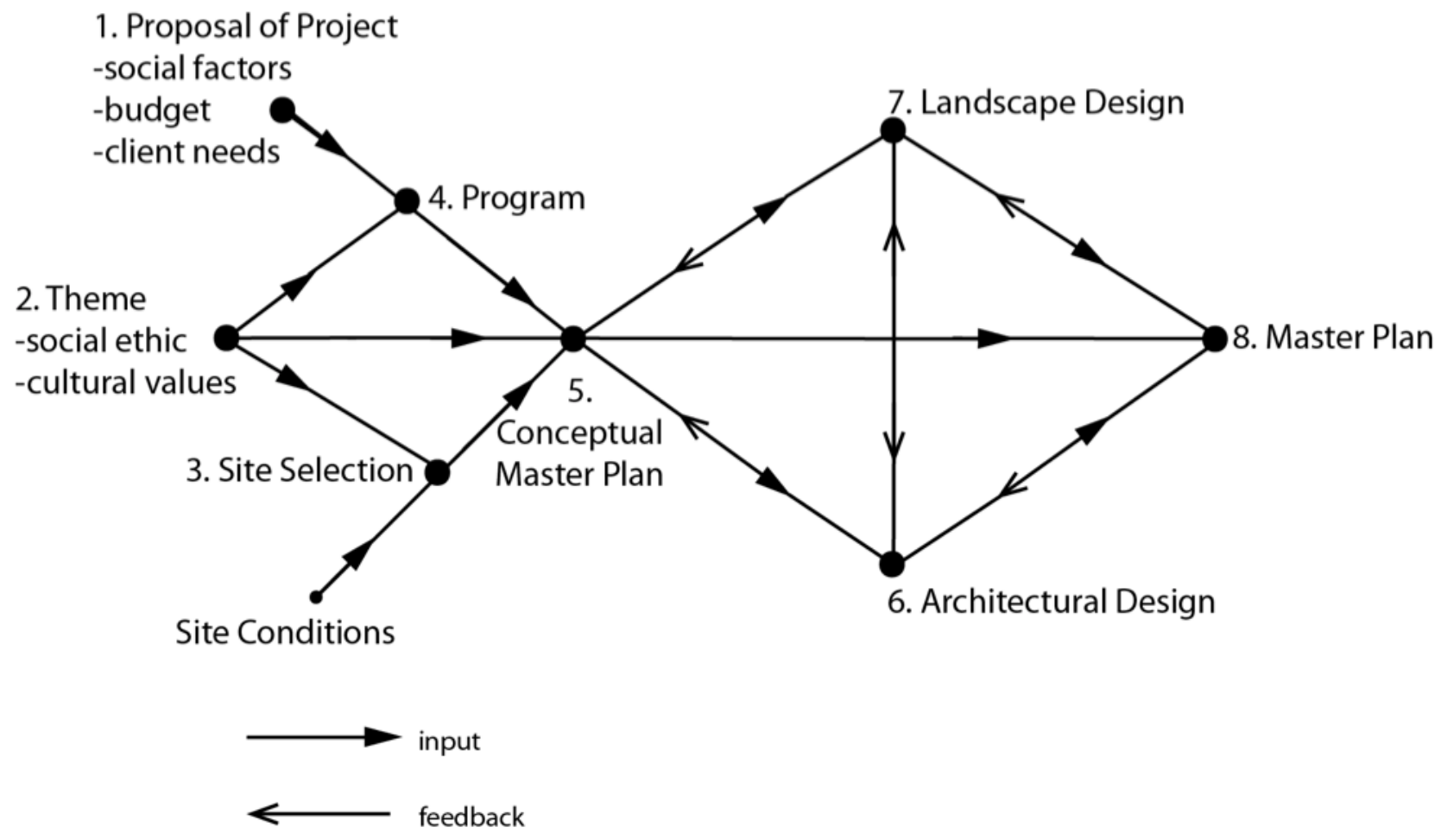

Figure 7. Integrative design process model for studio practice (by Ping $\mathrm{Xu}$ )

\subsection{Wind Pattern Study}

This studio studies wind patterns, wind blocks, and wind tunnels of Boulder, Colorado. With prevailing winds from the northwest, Boulder has some of the highest peak winds of any city in the US. Boulder's peak gusts have reached up to 143 miles per hour and regularly reach over 90 miles per hour [20]. Dry, warm, and down-sloping Chinook winds also prove to be a significant hazard, causing millions of dollars in damages each year in Boulder [14].

Wind is a highly dynamic system. Depending on local geographic characteristics, prevailing wind behavior will change. According to Olgyay [16], when a building's exposed side is positioned perpendicular to the wind direction, it receives the full force of the wind's speed. Rotating a building can reduce wind's impact by $50 \%$ when positioned at a $45^{\circ}$ angle. Accounting for the local wind patterns, students orientated their buildings to avoid the cold winter winds from the northwest and gain the summer breezes from the southwest.

Wind patterns must be considered when designing architectural forms. According to Figure 8, in both a building's plan and section, the force of the wind will be more intense in rectangular corners. After hitting the face of a building, wind's only path is around the nearest corner [16]. Design with consideration for wind patterns encompasses various scales from site selection to design issues and form, and also integrates architecture with plant design. The landscape design around buildings can positively impact the buildings interaction with wind patterns. Plants should be designed to direct and move cooling breezes into the building during the summer, and thick and tall plant materials should be utilized to create windbreaks from harsh winter winds.
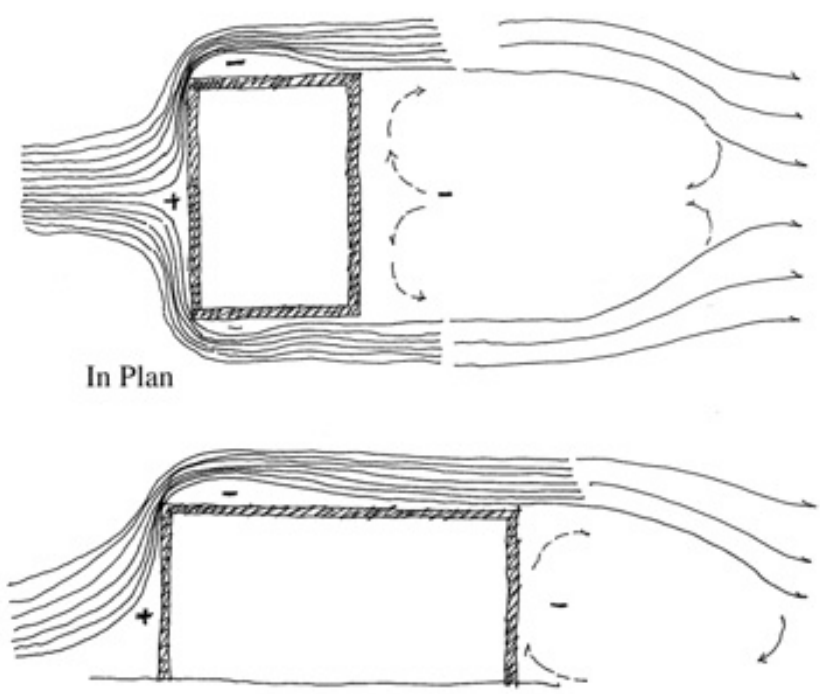

In Section

Figure 8. Rectangular building form and orientation affected by wind (Sketched by Ping Xu from Olgyay [16], 1963, pp. 103)

\subsection{Spatial Design and Synthesis}

The essential task of this studio is spatial design. In order to adapt to climate challenges, this studio emphasizes two aspects of spatial design, the first is creating forms that correspond to wind patterns, and the second is creating forms 
that make effective use of solar energy. Based on wind pattern research, a rectangular form is not the most functional for a building exposed to wind hazards. Supporting examples can be found during hurricanes in Florida where people have noticed that a house curved in both plan and section has a much better chance to survive than surrounding rectangular houses. The use of solar energy is an essential strategy to reducing carbon consumption, a major contributing factor to today's climate challenges. Boulder, Colorado has over 300 days or sun per year, and the area's extensive solar resources provide opportunities to further integrate solar energy into architecture. Solar energy does not need to be utilized by only putting panels on the roof of the building. The sun's angle is dynamic, and in response architecture can design dynamic forms that correspond to these angles. Considering solar orientation can contribute to the design of walls and windows as well, and create new architectural forms. Students integrate the knowledge of wind patterns and sun orientations into their architectural design. Taking into account these interdisciplinary requirements, students create functional spaces with fresh and meaningful appearances.

\section{Conclusions}

\subsection{Attitudes and Action toward Nature}

Recently extreme weather patterns and the increased frequency of natural disasters around the world have forced an understanding that nature holds greater power than humans. Figure 9 demonstrates a flowchart of the interaction between humans and nature. Mother Nature has both "the good face" of harvest and birth and "the bad face" of natural disasters and death. The natural environment provides resources for humans, allowing them to grow. With world populations increasing, humans exploit more natural resources than in the past. As a result, humans have broken the ecological balance. Nature takes on the face of revenge and causes more disasters, diseases, and deaths. During natural disasters, humans often feel powerless and useless. This echoes the feeling of ancient peoples. The primary difference is that ancient people created the religious means to control human demand of natural resources while contemporary people developed an ethical and ecological conscience to approach to sustainable solutions. Both groups have sought to find the best way to survive in and sustain the natural world. However, neither contemporary methods nor ancient worship can stop natural hazards from occurring. Human greediness in exploiting natural resources and attempts to conquer nature could cause more natural hazards. To prevent Mother Nature's revenge, contemporary people should respect ancient wisdom by not disturbing or "making nature angry." To inspire students to develop their ecological conscience and an environmental ethic is the essential aspect of architectural education in order to create a sustainable built environment.

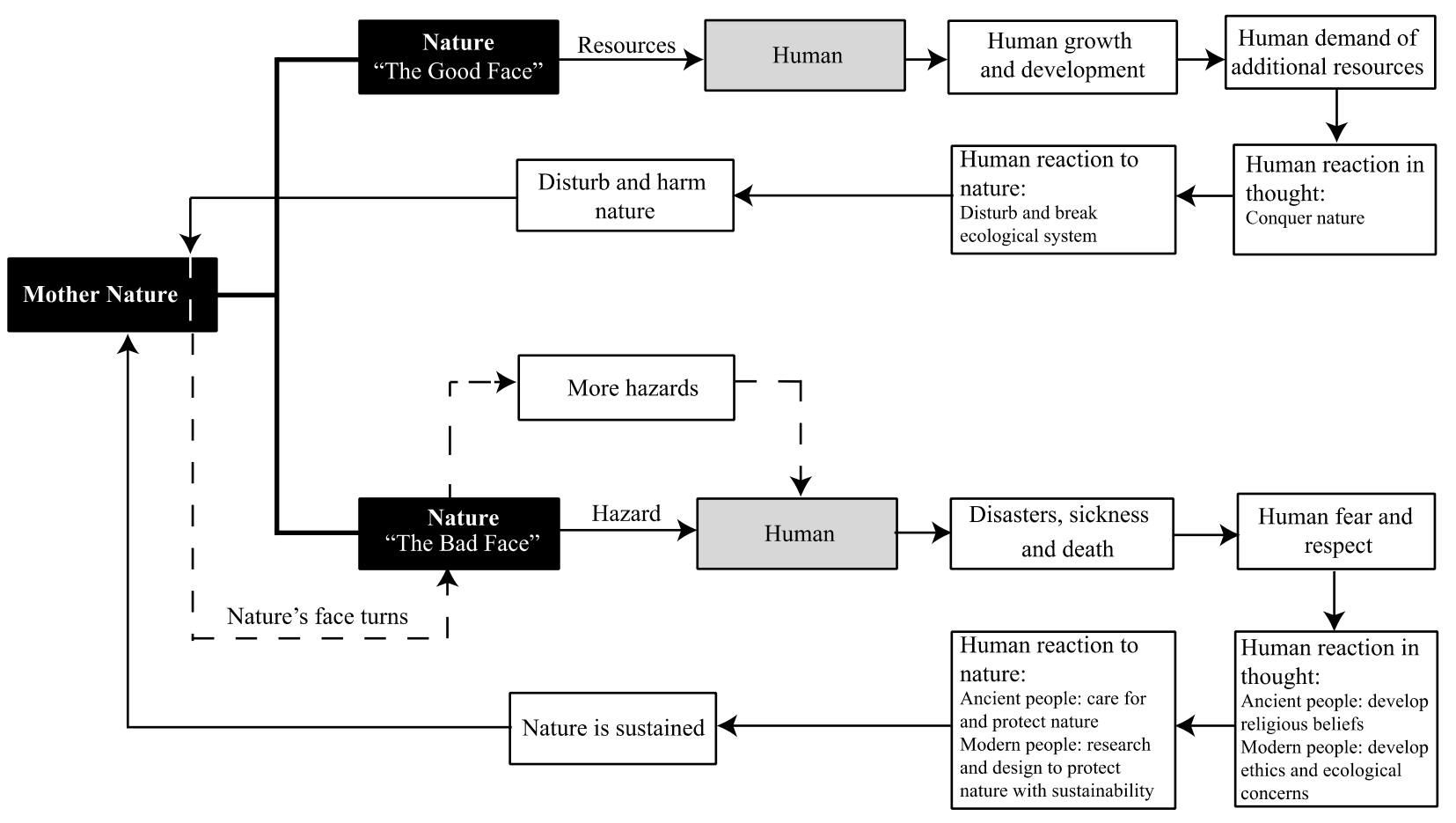

Figure 9. The interaction between humans and nature (By Ping Xu) 


\subsection{Suggestions}

Architectural education is now at a turning point. We are discovering the problems we have created, and further research is needed on why these problems occur and what their solutions will be. In architectural education, a curriculum that acknowledges adaptation to climate challenges is imperative to a synthesis approach to environmental design. Practicing in architectural studios for over a decade, the author suggests the following approach:

- Integrate the relevant knowledge of science and engineering solutions to deal with natural hazards. Many natural disasters are partially the result of humans acting without fully understanding natural law. Without taking into account climate challenges, thousands of people have been killed in houses that should have protected them.

- Conduct large-scale analyses in the design process, as natural disasters are often the result of patterns over broad regions. Landscape research and design with larger scale considerations will be crucial to avoid future failures $[7,19]$. Architectural education should be extended from building design to environmental concerns, and integrated with landscape planning using GIS (Geographic Information Systems). Such an approach would help to increase the resiliency of the built environment.

- Research global precedents and ancient wisdom in adaptation to climate challenges. Vernacular methods have tremendous value for sustaining civilizations [10]. Ancient people survived by adapting to natural laws based on thousands of years of experience. As Ian McHarg [13] said, "adaptations are primarily directed toward enhancing life and evolution." With increasingly extreme weather events, vernacular wisdom needs respect and an unbiased critique more than ever, as it could potentially lead to better solutions. These contents should be included in the curriculum of architectural design in order to develop new strategies for adapting to the changing environment.

- Synthesize the comprehensive knowledge of climate, engineering, and landscape analysis into spatial design.
Architects can create and manipulate forms that are attractive and follow scientific data. With sustainability as the goal, forms should follow scientific research strategies. Form is the medium to serve the goal. Architectural design should combine both creative and analytical approaches to develop a new design principle integrating solutions with technology and aesthetic values. With a synthesis knowledge base, architects, by the nature of their specialty, are capable of creating solutions for new types of architecture that adapt to climate challenges.

\subsection{Synthesis Approach to the Future of Education}

Olgyay [16] stated that climate ranks, with racial inheritance and cultural development, as one of the most crucial factors in determining the conditions of civilization. Figure 10 presents a framework for synthesis approaches in the past and future. When it comes to dealing with nature, humans behave with offensive and defensive actions. Ancient people feared and respected nature's power; developed belief systems and religions in accordance with it; and also exploited nature with available techniques. Over thousands of years, ancient people observed nature's revenge on human exploitation. To sustain their civilizations, ancient people have developed models, such as Chinese feng-shui, which synthesize their social and cultural values, follow the rules of nature, and account for human development patterns. These vernacular models are then applied to the built environment. However, contemporary ideas have tended to divide the fields of education and practice into increasingly more "silo" specializations in the pursuit of understanding. Isolating fields from their relevant elements and the environment of the systems, the "silo" approach, in turn, has created problems. In the $21^{\text {st }}$ Century, more and more scholars and professionals have endeavored to explore the interdisciplinary approach. Applying a synthesis approach will be the direction of the future of education and practice. 


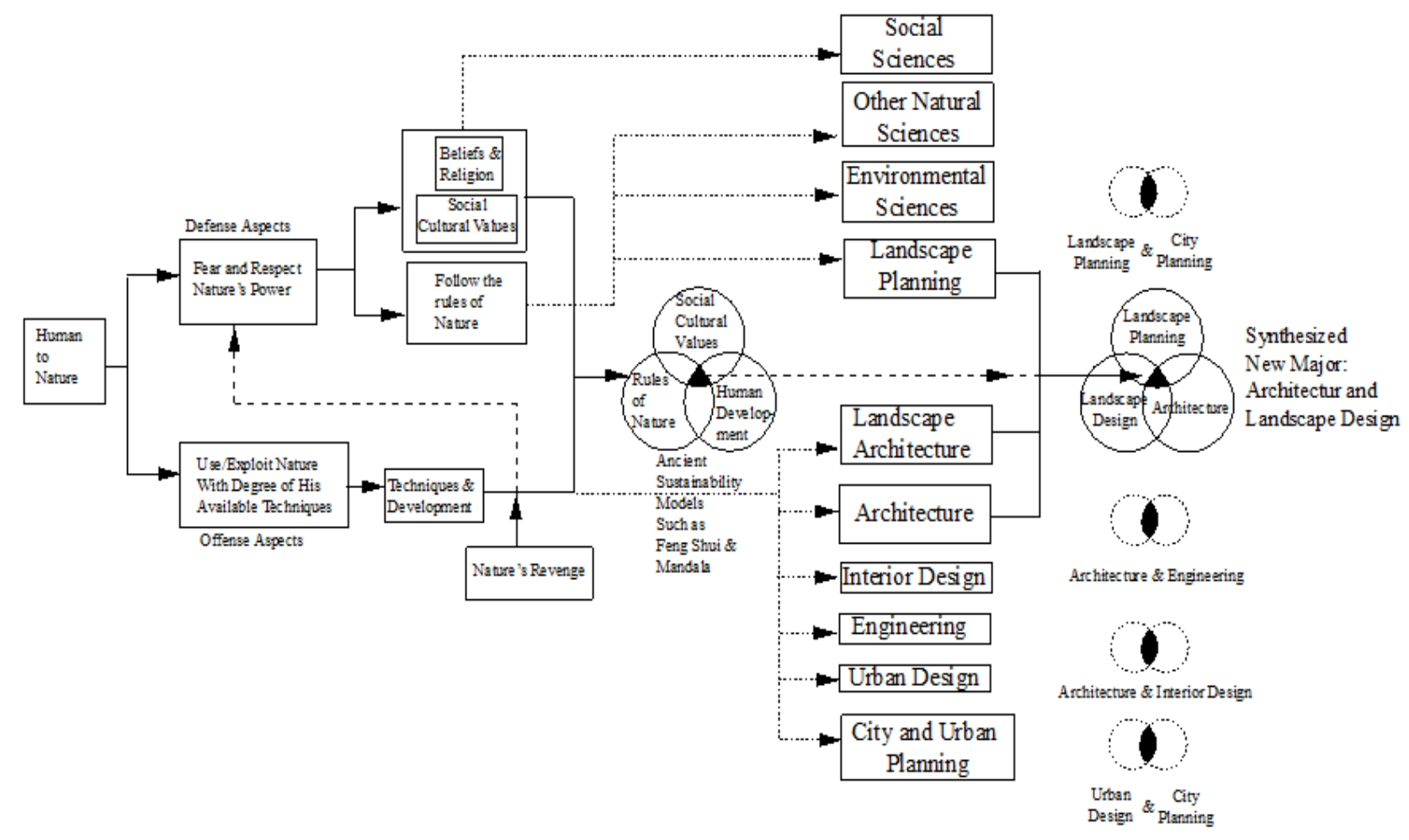

Figure 10. Synthesis approaches in the past and future (By Ping Xu)

\section{Acknowledgements}

The author would like to thank Mackinzi Taylor and Christian James Balan for editing this paper.

\section{REFERENCES}

[1] Aguilar, John and Bunch, Joey. "Two Years Later, 2013 Colorado Floods Remain a Nightmare for Some." The Denver Post, Denver: Digital First Media, September 12, 2015.

http://www.denverpost.com/2015/09/12/two-years-later-20 13-colorado-floods-remain-a-nightmare-for-some/

[2] Boulder County Site Plan Review Standards, Article 4-806 of Boulder County Land Use Code, Boulder County Land Use Department Publications, 2014.

http://www.bouldercounty.org/doc/landuse/spr03siteplanre viewstandards.pdf

[3] Costa, John E., and Gerald F. Wieczorek. Debris Flow/Avalanches: Process, Recognition and Mitigation. The Geological Society of America: Boulder, CO, 1987.

[4] Cui, P., Zhou, G.D., Zhu, X.H., Zhang, J.Q., Scale amplification of debris flows caused by cascading landslide dam failures, Geomorphology 182, Institute of Mountain Hazards and Environment: Chengdo, China, pp. 173-189, 2012.

[5] Darwin, Charles Robert. The Origin of Species, The Harvard Classics, New York: P.F. Collier \& Son, Vol. XI, 1909-14, 2001.
[6] Diakakis M.; Deligiannakis G.; Katsetsiadou K.; Lekkas E. "Hurricane Sandy mortality in the Caribbean and continental North America". Disaster Prevention and Management: an International Journal. $24 \quad$ (1): 132, 2015. doi:10.1108/DPM-05-2014-0082.

[7] Fisher, Thomas. Designing to Avoid Disaster: The Nature of Fracture-Critical Design, Routledge: Taylor \& Francis Group, New York and London, 2013.

[8] Golany, Gideon. Chinese Earth-Sheltered Dwellings: Indigenous Lessons for Modern Urban Design. University of Hawaii Press: Honolulu, 1992.

[9] Knabb, Richard D; Rhome, Jamie R; Brown, Daniel P; National Hurricane Center. Hurricane Katrina, Tropical Cyclone Report. United States National Oceanic and Atmospheric Administration's National Weather Service, 2005.

[10] Levi-Strauss C. (1962) The Savage Mind. Translated from French by George Weidenfeld. The University of Chicago Press: Chicago, 1966.

[11] Li, Ling. 中国方术概观 -- 后汉书 by 范晔 (398-445). People China Publisher: Beijing, 1993. (in Chinese)

[12] Liu, Ji. The Collection of the Ancient Texts, reprinting 50 historical famous masterworks from $200 \mathrm{BC}$ to 1600 AD., Fu Li Publisher: Taibei, 1986. (in Chinese)

[13] McHarg, Ian. Design with Nature, Doubleday \& Company, Inc: New York, 1971.

[14] Munoz, Rene. Boulder's Downslope Winds, UCAR, 2000. https://www.ucar.edu/communications/factsheets/winds.ht $\mathrm{ml}$ 
[15] Nebesky-Wojkowitz R. Oracles and Demons of Tibet: The Cult and Iconography of Tibetan Protective Deities. Lizenzausgabe des Verlages Mouton \& Co. Translated into Chinese 1996. Tibet People Publisher: Lhasa, 1975.

[16] Olgyay, Victor. Design with Climate: Bioclimatic Approach to Architectural Regionalism. Princeton University Press: Princeton, New Jersey, 1963.

[17] Onda, Yuichi. Hillslope hydrology and mass movements in the Japanese Alps. Mountain Geomorphology, ed. Philip N. Owens and Olav Slaymaker, pp.153-164. Arnold: London, 2004.

[18] Reneau, Steven L., and Dietrich, William E., The importance of hollows in debris flow studies; examples from Marin County, California, Debris Flow/Avalanches: Process, Recognition and, ed. J. E. Costa and G. F. Wieczorek, The Geological Society of America: Boulder, CO, pp. 165-179, 1987.

[19] Steinitz, Carl. A Framework for Geodesign: Changing Geography by Design, Esri: Redlands, CA, 2012.

[20] U.S. Department of Commerce National Oceanic and Atmospheric Association. Boulder Wind, 2012. http://www.ersl.noaa.gov/psd/boulder/wind/
[21] Wells, Wade G. The effect of fire on the generation of debris flows in southern California, Debris Flow/Avalanches: Process, Recognition and Mitigation, ed. J. E. Costa and G. F. Wieczorek, The Geological Society of America: Boulder, CO, pp. 105-114, 1987.

[22] Williams, Daniel E. Sustainable Design: Ecology, Architecture, and Planning. Hoboken, John Wiley \& Sons, Inc: New Jersey, 2007.

[23] Xu, Ping. Feng-shui models structure traditional Beijing courtyard houses, Journal of Architectural and Planning Research, Vol. 15:4, 271-282, 1998.

[24] $\mathrm{Xu}$, Ping. The Mandala as a cosmic model used to systematically structure the Tibetan Buddhist landscape. Journal of Architectural and Planning Research, Vol. 27:3, 181-203, 2010.

[25] Xu, Shike. Di Li Tian Ji Hui Yuan. The Shanghai Mountain House: Shanghai, 1580. (in Chinese)

[26] Ye, Jiusheng. Di Li Da Cheng. Jiu Jing Shu Jv: Shanghai, 1688. (in Chinese)

[27] Zou, Tingyou. Di Li Da Quan. The Shanghai Mountain House: Shanghai, 1676. (in Chinese) 